\title{
Pigmented Villonodular Synovitis Emerging From the Calcaneocuboid Joint in a 12 Year Old Female Child: A Case Report and Review of the Literature
} \author{
Panagiota $^{5}$, Vakaki Marina ${ }^{6}$, Hatzigiorgi Christiana ${ }^{7}$ \\ ${ }^{1}$ Department of Orthopaedics, Children's Hospital "P. \& A. Kyriakou”, Greece \\ ${ }^{2}$ Department of Orthopaedics, General Hospital “KAT", Greece \\ ${ }^{3}$ Department of Orthopaedics, General Hospital "G. Gennimatas", Greece \\ ${ }^{4}$ Department of Orthopaedics, University of Athens, Greece \\ ${ }^{5}$ Department of Pathology, Children's Hospital "P. \& A. Kyriakou”, Greece \\ ${ }^{6}$ Department of Ultrasound, Children's Hospital "P. \& A. Kyriakou", Greece \\ ${ }^{7}$ Department of Radiology, Children's Hospital "Aghia Sophia", Greece
}

Zambakides Christos ${ }^{1}$, ${ }^{*}$ Chalikias Stavros ${ }^{2}$, Soranoglou Vasileios ${ }^{3}$, Morassi Giuseppe Lampros ${ }^{4}$, Giamarelou

Submission: December 11, 2016; Published: December 20, 2016

*Corresponding author: Stavros Chalikias, Specialty Doctor Trauma and Orthopaedics, Raigmore Hospital, NHS Highland, Inverness Scotland, UK; Email: chalikias.stavros@gmail.com

\begin{abstract}
Pigmented villonodular synovitis (PVNS) is a benign idiopathic proliferative disorder that results in villous and/or nodular formations in the joints, tendon sheaths and bursae. We report a case of PVNS in a 12 year old female child with monoarticular involvement of the calcaneocuboid joint, an unusual location for this disease. The patient was treated successfully with open excision of the lesion and followed up for 4 years. We also present a concise literature review on diagnostic and treatment options for this rare synovial pathology.

Keywords: Calcaneocuboid joint; Children; Hemosiderin; Magnetic resonance; Pigmented villonodular synovitis; PVNS

Abbreviations: PVNS: Pigmented Villonodular Synovitis; U/S: Ultrasonography; T1WI: T1-Weighted Images; T2WI: T2-Weighted Images; MRI: Magnetic Resonance Imaging
\end{abstract}

\section{Introduction}

Pigmented villonodular synovitis (PVNS) was first described by Jaffe in 1941 [1] and it is a rare benign but locally destructive disease of yet unknown etiology. It is a proliferative disorder of the joint synovium that produces localized or diffuse nodular thickening of the synovial membrane [1-6]. Young adults in their third or fourth decade of life (range 20 - 50 years of age) are mainly affected with an estimated incidence of 1.8 cases per million. Distribution of the disease is variable among genders. PVNS usually involves a single joint, most commonly the knee. Although it can affect any joint, hip, ankle, small joints of foot and hand, shoulder and elbow are common locations in descending order of frequency [7-11]. Polyarticular cases have also been reported $[12,13]$. The incidence of PVNS in the foot and ankle is rare and assumed to be between $2.5 \%$ and $20 \%$ of all patients $[5,12,13]$.

The etiology of this condition remains controversial although many hypotheses have been proposed. Suggested causes of PVNS are chronic inflammation [1,14,15], benign neoplasia $[5,16]$, lipid metabolic disturbances $[10,17]$, or trauma with repeated hemorrhages [18]. A recent study demonstrated genetic correlation between PVNS and chromosome 7 trisomy [19]. Patients usually complain of regional pain, joint effusion and swelling, limitation of motion and increased local temperature $[5,6,9]$. Symptoms, if present, progress slowly. The purpose 


\section{Orthopedics and Rheumatology Open Access Journal}

of this study is to report our experience with the treatment approach and follow-up strategy of a young patient diagnosed with PVNS of the calcaneocuboid joint. The relevant literature was also reviewed. To our knowledge, only two cases of PVNS of the calcaneocuboid joint have been previously reported $[20,21]$.

\section{Case Presentation}

A 12-year-old well-nourished girl was presented to the outpatient department after her parents noticed a swelling in the dorsolateral region of her right midfoot. The swelling was first noticed three months before seeking medical advice. History of trauma was negative and patient's past and family medical history were unremarkable. The patient had no functional limitations or any other kind of complaints. During physical examination, a $3 \times 2 \mathrm{~cm}$, palpable, painless soft tissue mass was noted in the dorsolateral region of the right midfoot. The lesion was fluctuant and not adherent to the overlying skin. The range of motion of all joints was normal and there was no paraesthesia, numbness or any other neurovascular impairment.

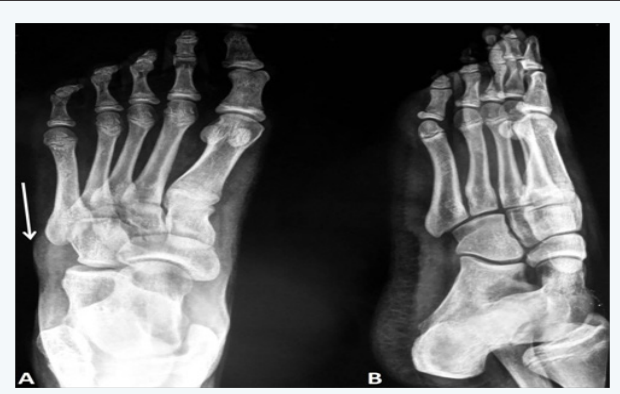

Figure 1: Anteroposterior (A) and oblique (B) foot radiographs Soft tissue swelling is clearly visible on the AP view (white arrow).

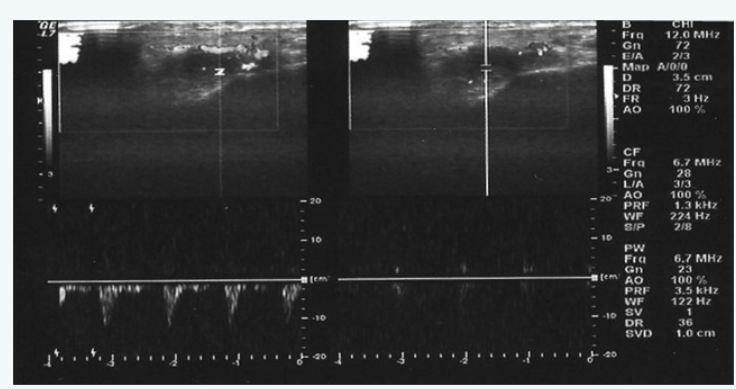

Figure 2: Preoperative ultrasound. At the area of the soft tissue swelling, a localized hypoechoic soft-tissue mass is depicted with multilobular margins and moderate internal vascularity. It appears connecting to the adjacent intraarticular space and causing mild concave deformation of the underlying bone.

Results of routine laboratory tests (including serum glucose, hemoglobin, white and red blood cell count, blood clotting, erythrocyte sedimentation rate and $\mathrm{C}$ reactive protein) were all normal. Plain X-rays revealed an ill-defined periarticular soft tissue mass without bone involvement (Figures 1A \& 1B) Ultrasonography (U/S) documented a hypoechoic mass with multilobular edges and moderate internal vascularization emerging from the underlining calcaneocuboid joint (Figure
2). Magnetic Resonance Imaging (MRI) study confirmed the soft tissue mass lateral to the calcaneocuboid joint, with low intensity signal on T1-weighted images (T1WI), heterogeneous low intensity signal on T2-weighted (T2WI) images and inconsistent enhancement after intravenous administration of a paramagnetic contrast agent (Figures 3A-3C).

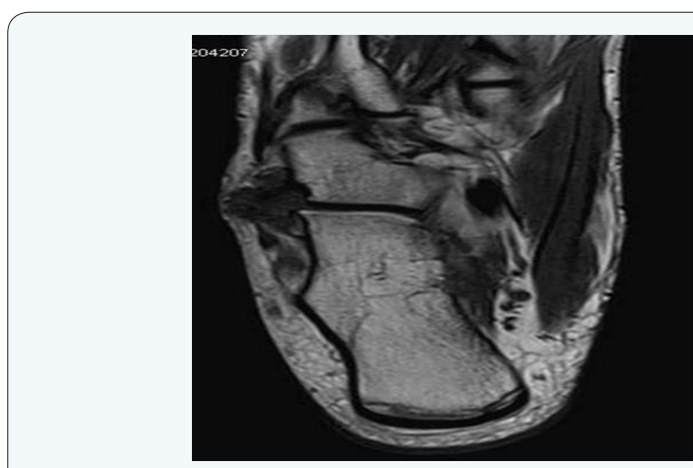

Figure 3A: Axial T1WI MR shows a lobulated mass of intermediate signal intensity lateral to the calcaneocuboid joint. There are no osseous erosions.

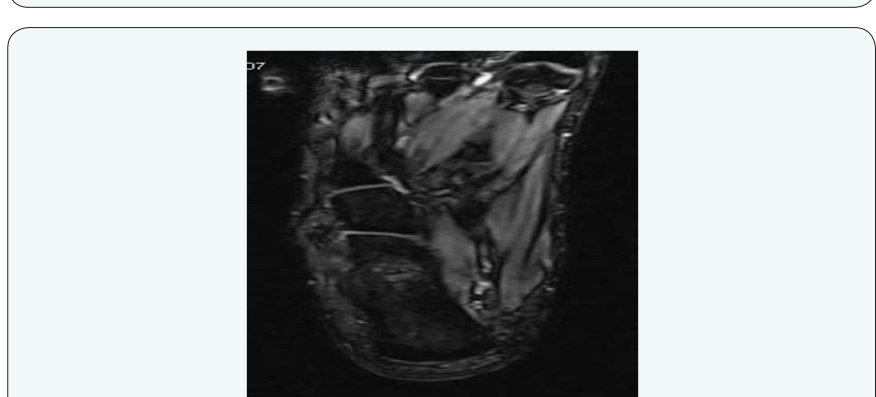

Figure 3B: Axial fl2d MRI shows heterogenous lobulated mass of high and low signal intensity.

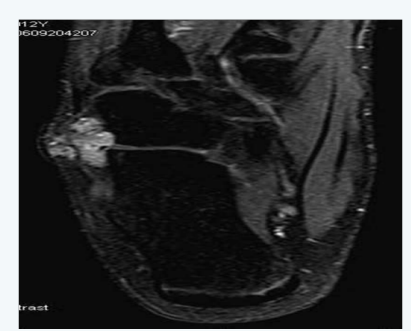

Figure 3C: Axial T1WI FS after intravenous administration of paramagnetic contrast agent, shows intense enhancement of the mass.

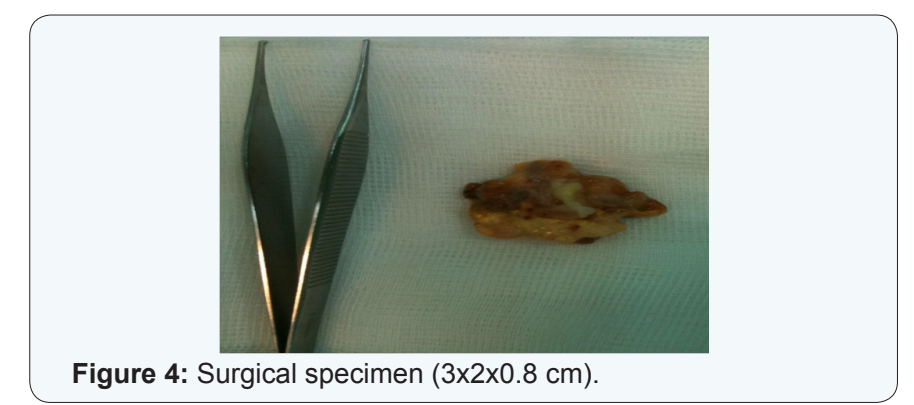

The patient underwent an open excisional biopsy through a lateral approach under general anaesthesia and tourniquet 


\section{Orthopedics and Rheumatology Open Access Journal}

control. A yellowish and partly brownish, multilobulated, irregular mass ( $3 \times 2 \times 0.8 \mathrm{~cm}$ ) was excised (Figure 4) and sent for pathology evaluation. Histologically, the specimen consisted mainly of nodular rather than villous lesions. Multiple cells similar to the synovial ones with increased mitotic activity and eosinophilic cytoplasm were revealed. Hemosidirin positive histiocytes of chronic inflammation also co-existed, while there were also sites of xanthochromatic cells (Figures 5A \& 5B). Immunohistochemical staining was positive for CD68 and MAC387 antibodies. Diagnosis of PVNS was documented.

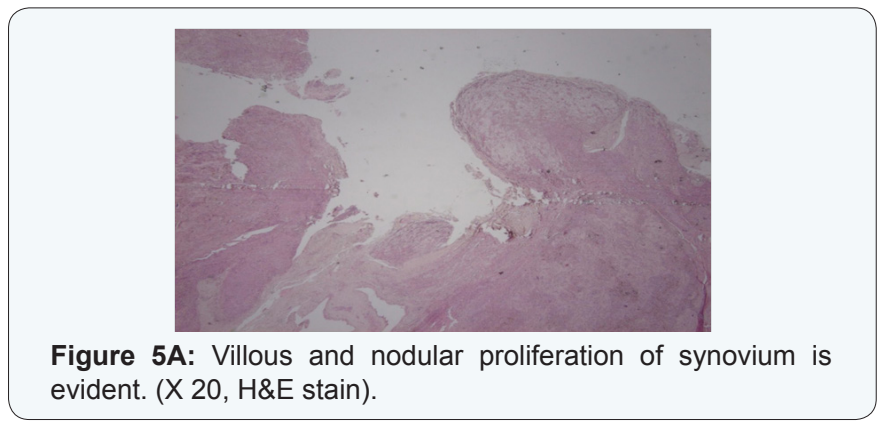

Figure 5A: Villous and nodular proliferation of synovium is evident. (X 20, H\&E stain).

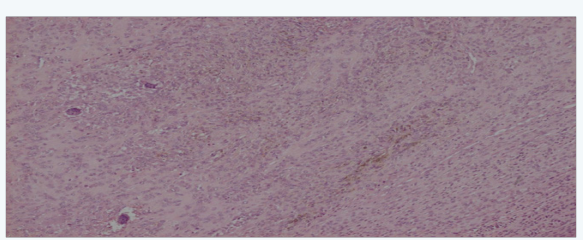

Figure 5B: Histiocytic infiltration into synovium and focal hemosiderin deposition. Osteoclast - like giant cells are characteristic of this lesion. (X 200, H\&E stain).

The patient was discharged on postoperative day 1. Clinical follow-up evaluation took place at two weeks and three months, then every two months during the first year and afterwards every six months at our outpatient department. Follow-up U/S was performed by the same radiologist at 3, 5, 7 and 17 months postoperatively. The first U/S evaluation revealed a hypoechoic mass with mild vascularity measured $1.15 \times 0.51 \times 0.93 \mathrm{~cm}$ which, 17 months postoperatively, was decreased in size to 0.95 x 0.6 x $0.6 \mathrm{~cm}$ without any vascular congestion (Figure 6). MRI was performed at one and two years postoperatively, revealing no recurrent mass (Figure 7). The last follow-up visit was at 4 years with an unremarkable clinical examination and the patient remained consistently free of symptoms.

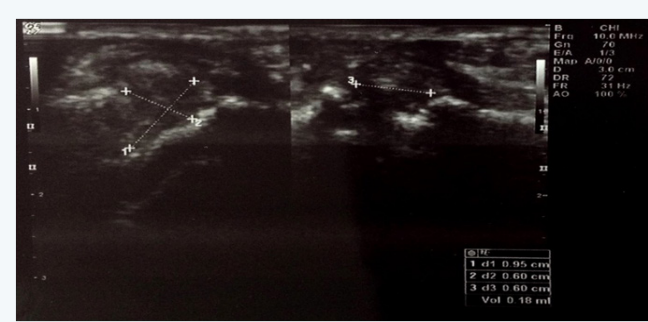

Figure 6: At 17 months follow-up, a small residual intraarticular soft-tissue mass with no detectable internal blood flow, $0.95 \times 0.60 \times 0.60 \mathrm{~cm}(0.18 \mathrm{ml})$ is demonstrated on ultrasound.

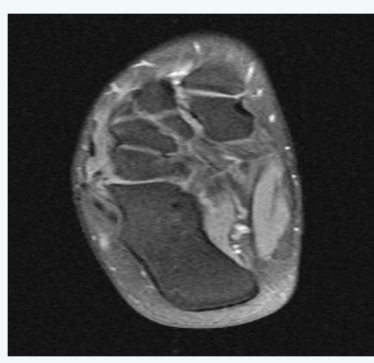

Figure 7: MRI scan, at 12 months follow-up.

\section{Discussion}

PVNS is a rare disease encountered mostly among young adults, without any sex predominance. It is even rarer in children. Involvement of foot is infrequent with an incidence of $2.5 \%$ to $20 \%$. The majority of current literature is focused on PVNS of the knee. Diagnosis is often delayed because of the insidious and unspecific mode of presentation and the subtle initial radiographic findings. Pain, inflammation and joint effusion are common presenting symptoms and signs with variable duration [22].

Preoperative confirmation of PVNS consists of X-ray imaging, which is likely to be false negative, computed tomography, U/S and MRI. MRI is the modality of choice for the diagnosis and determination of the damage extent to the bone and the local soft tissue. Additionally, MRI seems to be the gold standard for the postoperative imaging follow-up. The extent of the abnormality may appear larger than its actual size -"blooming phenomenon"- because of the magnetic susceptibility effect caused by hemosiderin [9]. Regarding the present case, MRI was much more helpful than U/S. MRI findings consisted of low signal intensity images on all sequences because of the paramagnetic effect of hemosiderin, along with hyperplastic synovium [23].

Treatment depends on whether the lesion is diffuse or localized. Total, open or arthroscopic, synovectomy is indicated in the diffuse form. Local excision is indicated for the localized form. The mechanism of bone erosion in PVNS is still under debate. A possible mechanism is increased pressure within involved joints because of synovial overgrowth. Other researchers believe that perhaps the synovium releases a substance that causes bone erosion. Whatever the cause is, bone erosion results in joint destruction [24,25]. Treatment options like arthroplasty and arthrodesis should then be considered, usually in older patients.

For recurrent PVNS, usually due to incomplete excision [26], re-excision is recommended and the use of radiotherapy, external or intraarticular (isotopic synoviorthesis), is also indicated as an adjunct [2,9]. However, there is skepticism regarding the use of radiation on children. Moreover, surgeons should watch for local complications, such as postradiation fibrosis, swelling, and wound-healing problems, along with risks to bone graft incorporation if it is necessary later [27]. Malignant transformation after radiotherapy is a worrisome adverse effect, especially in young patients. In reports of malignant PVNS, there 
is often previous history of radiotherapy [28]. In extremely recurrent cases, amputation has also been described [29]. When involving the foot, the treatment of choice is total excision, usually with very low rates of recurrence $(0 \%$ to $16 \%)$ [20].

After the excision, the diagnosis is finally documented histologically, as the PVNS lesions include synovial hyperplasia, hypervascularity and hemosiderin-laden histiocytes. All the histological criteria must be fulfilled by the surgical specimen in order to establish the diagnosis, on the grounds that PVNS is an over diagnosed entity [30].

Differential diagnosis is critical, and should include all the similar soft tissue tumors, along with all types of synovitis, rheumatoid arthritis, tuberculosis, haemophilia, malignant synovialoma, giant cell tumors, ganglion, hemangioma, lipoma and also traumatic lesions [23].

\section{Conclusion}

PVNS is a rare disease in the pediatric population. Because of its subtle symptoms, it should be taken into consideration in every case of atraumatic hemarthrosis and swelling of a joint, because delay may lead to secondary degenerative joint disease. MRI findings and pathology exam of the gross specimen should guide the correct diagnosis. The treatment is surgical, depending on the type of the disease. In recurrent cases, especially in the diffuse form despite re-excision, the application of external or intraarticular radiation therapy should be additionally considered. MRI is the modality of choice for imaging followup, in order to detect potential recurrence, since the U/S, even when performed by the same sonographer, is not always reliable postoperatively.

\section{References}

1. Jaffe HL, Lichtenstein L, Sutro CJ (1941) Pigmented villonodular synovitis, bursitis and tenosynovitis Arch Pathol 31: 731-65.

2. Dorwart RH, Genant HK, Johnston WH, Morris JM (1984) Pigmented villonodular synovitis of synovial joints: clinical, pathologic and radiologic features. AJR Am J Roentgenol 143(4): 877-885.

3. Myers BW, Masi AT (1980) Pigmented villonodular synovitis and tenosynovitis: a clinical epidemiologic study of 166 cases and literature review. Medicine (Baltimore) 59(3): 223-238.

4. Schwartz HS, Unni KK, Pritchard DJ (1989) Pigmented villonodular synovitis: a retrospective review of affected large joints. Clin Orthop Relat Res 247: 243-255.

5. Rao AS, Vigorita VJ (1984) Pigmented villonodular synovitis (giant cell tumor of tendon sheath and synovial membrane): a review of eightyone cases. J Bone Joint Surg Am 66(1): 76-94.

6. Dürr HR, Stäbler A, Maier M, Refior HJ (2001) Pigmented villonodular synovitis. Review of 20 cases. J Rheumatol 28(7): 1620-1630.

7. Chin KR, Barr SJ, Winalski C, Zurakowski D, Brick GW (2002) Treatment of advanced primary and recurrent diffuse pigmented villonodular synovitis of the knee. J Bone Joint Surg Am 84(12): 2192-2202.

8. Miller WE (1982)Villonodular synovitis: pigmented and nonpigmented variations. South Med J 75 (9): 1084-1086.
9. Mendenhall WM, Mendenhall CM, Reith JD, Scarborough MT, Gibbs CP, et al. (2006) Pigmented villonodular synovitis. Am J ClinOncol 29(6): 548-550.

10. Granowitz SP, D'Antonio J, Mankin HL (1976) The pathogenesis and long-term end results of pigmented villonodular synovitis. Clin Orthop Relat Res 114: 335-351.

11. Klompmaker J, Veth RP, Robinson PH, Molenaar WM, Nielsen HK (1990) Pigmented villonodular synovitis. Arch Orthop Trauma Surg 109(4): 205-210.

12. Gehweiler JA, Wilson JW (1969) Diffusebiarticular pigmented villonodular synovitis. Radiology 93(4): 845-851.

13. Milton L Wagner, Harlan J Spjut, Robert V Dutton, Arthur L Glassman, Julius B Askew (1981)Polyarticular pigmented villonodular synovitis. AJR Am J Roentgenol 136(4): 821-822.

14. Sakkers RJ, deJong D, Van der Heul RO (1991) X-chromosome inactivation in patients who have pigmented villonodular synonitis. J Bone Joint Surg Am 73(10): 1532-1536.

15. Fred Flandry, Lyle A Norwood (1989) Pigmented villonodular synovitis of the shoulder. Orthopedics 12(5): 715-718.

16. Choong PF, Willen H, Nilbert M, Mertens F, Mandahl N, et al. (1995) Pigmented villonodularsynonitis. Monoclonality and metastasis - a case for neoplastic origin? Acta Orthop Scand 66(1): 64-68.

17. J Klompmaker, RPH Veth, PH Robinson, WM Molenaar, HKL Nielsen (1990) Pigmented villonodular synovitis. Arch Orthop Trauma Surg 109(4): 205-210.

18. Singh R, Grewal DS, Chakravarti RN (1969) Experimental production of pigmented villonodular synovitis in the knee and ankle joints of rhesus monkeys. J Pathol 98(2): 137-142.

19. Fletcher JA, Henkle C, Atkins L, Rosenberg AE, Morton CC (1992) Trisomy 5 and trisomy 7 are nonrandom aberrations in pigmented villonodular synovitis: confirmation of trisomy 7 in uncultured cells. Genes Chromosomes Cancer 4(3): 264-266.

20. Freedman BA, Lin DL, Tis JE (2007) Pigmented villonodular synovitis of the calcaneocuboid joint in an 11-year-old child with subtalar coalition. Foot Ankle Int 28(4): 511-515.

21. Duncan N, Rajan R (2015) Case report of pigmented villonodular synovitis arising from the calcaneocuboid joint in a 12 year old male. Foot (Edinb) 25(1): 59-61.

22. Baroni E, Russo BD, Masquijo JJ, Bassini O, Miscione H (2010) Pigmented villonodular synovitis of the knee in skeletally immature patients. J Child Orthop 4(2): 123-127.

23. Eckhart BP, Hernandez RJ (2004) Pigmented villonodular synovitis: MR imaging in pediatric patients. Pediatr Radiol 34(12): 943-947.

24. Nishida Y, Tsukushi S, Nakashima H, Sugiura H, Yamada Y, et al. (2012) Osteochondral destruction in pigmented villonodular synovitis during the clinical course. J Rheumatol 39(2): 345-351.

25. Bhimani MA, Wenz JF, Frassica FJ (2001) Pigmented villonodular synovitis: keys to early diagnosis. Clin Orthop Relat Res 386: 197-202.

26. Ushijima M, Hashimoto H, Tsuneyoshi M, Enjoji M (1986)Pigmented villonodular synovitis. A clinicopathologic study of 52 cases. Acta Pathol Jpn 36(3): 317-326.

27. Brien EW, Sacoman DM, Mirra JM (2004) Pigmented villonodular synovitis of the foot and ankle. Foot Ankle Int 25(12): 908-913.

28. Hye-Jung Yoon, Young-Ah Cho, Jae-Il Lee, Sam-Pyo Hong, SeongDoo Hong (2011) Malignant pigmented villonodular synovitis of the temporomandibular joint with lung metastasis: a case report and 
review of the literature. Oral Surg Oral Med Oral Pathol Oral Radiol Endod 111(5): e30-e36.

29. Bruns J, Schubert T, Eggers-Stroeder G (1993) Pigmented villonodular synovitis in children. Arch Orthop Trauma Surg 112(3): 148-151.
30. Kooij N, Shadid MB, Castelein RM, van Diest PJ (2009) Pigmented villonodular synovitis: an overdiagnosed entity. Histopathology 55(4): 477-478.

\begin{tabular}{l} 
Your next submission with JuniperPublishers \\
will reach you the below assets \\
- Quality Editorial service \\
- Swift Peer Review \\
- Reprints availability \\
- E-prints Service \\
- Manuscript Podcast for convenient understanding \\
- Global attainment for your research \\
- Manuscript accessibility in different formats \\
( Pdf, E-pub, Full Text, A udio) \\
- Unceasing customer service \\
Track the below URL for one-step submission \\
http://juniperpublishers.com/online-submission.php \\
\hline
\end{tabular}

